\title{
HAICAIS NA COMPOSIÇÃO POÉTICA DE EDUARDO MAHON
}

\section{HAICAIS IN THE POETIC COMPOSITION OF EDUARDO MAHON}

\author{
Sandra Maria Alves de Souza ${ }^{1}$
}

Recebido em: 14 abr. 2020.

Aceito em: 22 jul. 2020.

DOI 10.26512/aguaviva.v5i2.30907

RESUMO: O objetivo deste artigo é realizar uma análise interpretativa nos textos poéticos do escritor matogrossense Eduardo Mahon com foco no fazer poético, observando o estilo do autor, destacando sua preferência pelos haicais em sua composição, observando, também, sua despreocupação com a estrutura fixa, provocando uma ruptura na forma tradicional. Para tal, utilizar-se-ão dos poemas da sua trilogia Meia Palavra Vasta (2014), Palavra de Amolar (2015) e Palavrazia (2015). Esta é uma pesquisa qualitativa de cunho crítico reflexiva sobre questões que envolvem o texto poético desse escritor. Teóricos como Bosi (1977), Antônio Candido (1996) entre outros contribuem para essa reflexão.

Palavras-chave: Haicais. Poemas contemporâneos. Eduardo Mahon.

\begin{abstract}
The purpose of this article is to perform an interpretative analysis of the poetic texts of Mato Grosso writer Eduardo Mahon focusing on the poetic making, observing the author's style, highlighting his preference for haiku in his composition, also observing his unconcern with the fixed structure, causing a break in the traditional form. For this, we will use the poems of the trilogy Meia Palavra Vasta (2014), Palavra de Amolar (2015) e Palavrazia (2015). This is a qualitative research of reflective critical nature on issues involving the poetic text of this writer. Theorists such as Bosi (1977), Antônio Candido (1996) and others contribute to this reflection.
\end{abstract}

Keywords: Haiku. Contemporary Poems. Eduardo Mahon.

\footnotetext{
${ }^{1}$ Possui graduação em Letras - Português com habilitação em Língua Inglesa (2007) pelo Centro de Ensino Superior de Maringá (CESUMAR) e Pós-Graduação Lato Sensu (2009) Pela UNIFLOR no curso de Língua Portuguesa e Literatura Brasileira. É professora na Educação Básica de ensino em Língua Estrangeira- Inglês Secretaria de Estado de Educação do Estado do Mato Grosso (SEDUC/MT). E-mail: sandrinhamariasouza@hotmail.com
} 


\section{CONSIDERAÇÕES INICIAIS}

Eduardo Moreira Leite Mahon nasceu no dia 12 de abril de 1977 no Rio de Janeiro e mora em Cuiabá, Mato Grosso, desde 1980. Possui um total de 14 obras publicadas, entre elas estão romances, contos e poesia. É matogrossense pela sua vivência, experiência e, principalmente, pela sua contribuição na produção de obras literárias que enriquece e fortalece a cultura brasileira e, principalmente, regional.

Poeta contemporâneo pelo seu estilo literário e as temáticas voltadas para o existencialismo, ele traz uma reflexão gerada no homem pós-moderno com reflexões de forma irônica, humorística e, por vezes, crítica com questões que afligem o ser humano no mundo contemporâneo.

Mahon gosta de "brincar" com as palavras, com uma linguagem interativa e dinâmica, trazendo em seus textos reflexões sobre o comportamento do homem contemporâneo. É um admirador dos poetas contemporâneos Arnaldo Antunes e Nilton Manuel, cujas obras contribuíram de forma significante e inspiradora na composição de seus poemas.

Os temas apresentados na trilogia, Meia Palavra Vasta (2014), Palavra de Amolar (2015) e Palavrazia (2015), são atuais e, de forma descontraída, o escritor envolve o leitor numa reflexão sobre futilidade da vida e das coisas. A ironia é recorrente em seus poemas que apresentam, também, crítica da perplexidade sobre o comportamento do homem moderno na sociedade.

O poeta utiliza nessa trilogia, na maioria dos poemas, versos e estofes curtas, poesia existencial e reflexiva de poemas escritos apenas com três versos denominados de haicais, poemas concisos e objetivos. Por ter essa característica, o poeta se vê obrigado a sintetizar a ideia de forma poética com originalidade, trazendo uma mensagem de forma a cativar o leitor, onde ele decompõe e recompõe as palavras que se desdobram em significados.

O haicai é de origem japonesa e, também, é conhecido com haiku. É um poema curto formado por dois termos "hai" brincadeira e o "kai" harmonia, um poema humorístico. Composto ao todo por 17 sílabas poéticas, sendo uma estrofe de três versos. A estrutura dos versos são cinco sílabas no primeiro e no terceiro verso, e o segundo verso com sete sílabas, dispostos numa estrofe, que se refere a cada estação do ano, fazendo menção em que época do ano o poema foi escrito.

Com o passar do tempo, o haicai perdeu sua essência de retratar as estações do ano, conhecida como Kigô, e sua composição se tornou menos rígida, perdendo sua tradição e 
ganhando liberdade poética, sem preocupação com a métrica, rima e, principalmente nos temas. Para Paz (1990), o Japão, para o poeta moderno, torna-se “[...] não um espelho, mas uma janela que mostra outra imagem do homem, outra possibilidade de ser" (PAZ, 1990, p. 204).

Assim, no final do século XVII, Basho estabeleceu as principais características do haicai com temas que abordam a natureza, solidão, simplicidade e a ausência do sentimentalismo. $\mathrm{O}$ escritor Bashô que fez dessa forma poética uma arte refinada, uma poética admirável. Escrever esse tipo de poema torna-se um desafio, pois havia dificuldade em reproduzir essas sílabas poéticas, uma vez que a estrutura fixa do haicai envolve, não somente estrutura, mas, também, o conteúdo.

A rapidez do mundo moderno e a necessidade de captar as coisas no momento exato, fez com que alguns poetas modernistas brasileiros optassem pelo haicai. Queiroz (2002, p. 65) diz que alguns escritores preferem o haicai por possuir "Leveza, brevidade e concisão vocabular, capacidade de flagrar instantes fugidios da vida, qualidade do olhar e filosofia do cotidiano".

Assim, o poeta mato-grossense dá preferência aos haicais em sua composição poética substantivando as palavras para produzir efeito no sentido de provocar o leitor. Já dizia Manoel de Barros, poeta pantaneiro, mato-grossense e, também, um dos principais poetas da modernidade, que "a poesia está guardada nas palavras".

Por isso, Mahon, ao compor o poema, procura selecionar as palavras, pois "quanto menos tradicional a poesia queira ser, tanto mais se distancia da frase como forma tradicional articulada pelo sujeito, objeto, predicado verbal, preposições etc.” (FRIEDRICH, 1978, p. 153).

Os poemas são de poucos versos e com poucas palavras, porém selecionadas e lapidadas como se faz com o ouro para produzir uma joia rara, gerando beleza e admiração, tornando cada palavra valiosa e seu significado intenso causando dúvidas, incertezas. Por vezes, o escritor se vale da ironia e por outras, do humor. Nesse sentido, Salvatore D’onofrio (2005, p. 113) acrescenta que "o haicai apresenta o espetáculo da vida de uma forma surpreendente mediante associações alógicas" por isso que, às vezes, causa desconforto na leitura de alguns poemas.

O poeta faz várias experimentações criativas, ocorrendo uma variação no aspecto formal, demonstrando seu gosto com poemas concretos, blocos de estrofes e, principalmente, haicais com o uso do verso livre, sem preocupação com a métrica e a estrutura formal dos poemas.

\section{Trilogia de poema experimental, metapoético e lúdico}


O autor afirmou à imprensa da Vida-gazeta digital, em uma redação escrita por Angélica Moraes, na plataforma da Academia Mato-grossense de Letras em abril de 2016, quando se referia o lançamento da trilogia em Cuiabá, que a obra Meia Palavra Vasta (2014) é mais experimental, pois lida com a metapoesia e experimentos aleatórios, já no Palavras de Amolar (2015) a crítica se acentua vivamente, refletindo suas próprias impressões sobre literatura e, finalmente, no Palavrazia (2015), há mais ludicidade.

A poeta Marli Walker observa no prefácio do livro Palavrazia (2015) que 'apesar da aspereza, da ironia e da crítica presentes em sua poesia, Eduardo Mahon sabe que só há “astúcia/em palavras de pelúcia”. Essa obra "Apresenta uma síntese que se desdobra em humanismo de extensão singular e profundo, um tecido de poucas linhas que significam muitas páginas" (NETO, 2015).

Já a poeta Marilza Ribeiro com suas contribuições no prefácio do livro Palavra de Amolar (2015) coloca que:

$\mathrm{Na}$ construção das palavras como um movimento lúdico, compondo significados, prazeres, tristezas, assombros, admiração, Eduardo Mahon consegue recompor em nós o alivio da nossa inquietude, na invenção e ordenação dos signos, por entre textura do vocabulário poético... combina e recombina as palavras, rimas e ritmos na ginga as sensações e malicias afloradas. Ele rege essa sinfonia exuberante de uma estética que nos enleva, encanta, diverte e erotiza (RIBEIRO, 2015 apud MAHON 2015 s/p.).

Da mesma forma, a escritora Cristina Campos comenta no prefácio do livro Meia Palavra Vasta (2014) que os poemas de Mahon:

Poderia corresponder à criativa proposta fórmula de engolir uma pílula oswaldiana: rápida de engolir e de fácil digestão. Mas o adjetivo, vasta, promete algo distinto: economia vocabular com potência expansiva, mansa marola, ou tsunami explosivo. Ao mesmo tempo a similaridade vasta/basta semanticamente saltava para a sugestão qualificativa de uma palavra pequena (talvez amputada em fragmentos), porem exata, precisa, lapidada com cinzel ao modo clássico (CAMPOS, 2014 apud MAHON, 2014 s/p.).

Cristina Campos comparou os poemas de Mahon com o estilo de Oswald de Andrade. Esse poeta foi um dos representantes da Arte Moderna em 1922, fundou o movimento antropofágico com o objetivo de acabar com a literatura que não fosse considerada brasileira. 
A obra do escritor Oswald de Andrade foi a única que inclui todas as características do movimento modernista, pois foi através da arte que ele conseguiu transgredir, polemizar e quebrar parâmetros estabelecidos por outros movimentos literários com espirito inovador, sempre com seu lado crítico e irônico em suas produções retratando o social da época. O uso da linguagem coloquial e o predomínio dos versos livres são características do movimento, bem como, a ocorrência na obra de Andrade.

Mahon é modernista, por aderir a essas características em sua trilogia, além da criticidade e da ironia que são recorrentes em seus poemas e seu estilo se aproxima do poeta Oswald de Andrade. Ademais, é um admirador dos poetas contemporâneos Arnaldo Antunes e Nilton Manuel, cujas obras contribuíram de forma significante e inspiradora na composição de seus poemas.

É inovador, rompe com valores e com o estilo tradicional, preferindo um estilo mais livre "vanguarda/ é forma/ à margem da norma". Paz (1990) afirma que a ruptura da tradição se manifesta através da negação de outra tradição que se configura com a nova, diferente, assim, o moderno tem autonomia em sua produção, promovendo uma descontinuidade da tradição passada.

Por isso, a preferência do escritor pelo uso de uma linguagem simples e cotidiana, escolha vocabular, estrutura curta dos poemas e temas atuais abordados na trilogia. Fica evidente que ele aderiu aos modernistas, desprezando a tradição da arte clássica.

Edgar Alan Poe (1985) afirma sobre a estrutura da sua obra $O$ corvo (1845), no livro Filosofia da Composição, que o poeta antes de iniciar sua produção precisa esquematizar os elementos de modo que eles se combinem e que tenham uma sequência lógica como um problema matemático. Do mesmo modo, Eduardo Mahon concedeu uma entrevista no site “Como eu escrevo", realizado por ${ }^{2}$ José Nunes em janeiro de 2019, que tudo deve ser pensado antes de começar a produção, ele escreve os monoblocos e com a estrutura, o roteiro delineado e a estratégia montada, daí sai a primeira versão. Diz Mahon, "Não sou maluco ao ponto de entrar num navio sem um mapa".

Poe, um grande escritor e crítico literário, ao compor uma obra, preocupava-se com o público burguês, e os próprios críticos da época, sobre como sua obra seria recepcionada, assim, suas produções eram arquitetadas e pensadas como um problema matemático, de forma a impressionar seus leitores, provocando reação imediata.

\footnotetext{
2 José Nunes. Como escreve Eduardo Mahon. Nunes é doutorando em direito na Universidade de Brasília. Disponível em: https://comoeuescrevo.com/eduardo-mahon/. Acesso em 04 nov. 2019
} 
Nessa trilogia, a preocupação de Mahon não é de agradar ao público, muito menos os críticos. O escritor coloca "um crítico arisco/ despreza o olho/ para olhar o cisco" pois seus poemas fazem justamente o contrário, eles incomodam, perturbam, interrogam, causando desconforto no leitor " a minha poesia/ tem por projeto:/ uma arquitetura/ sem arquiteto".

O escritor afirma que "a trilogia é aberta o suficiente para ser interpretada independentemente da minha vontade ou intenção. Quero que os textos sejam adotados pelos leitores, cada qual com sua própria razão", diz Mahon em um depoimento para a Gazeta digital em 2016. Na trilogia, as obras não são paginadas, criando uma sensação de liberdade de leitura, ao mesmo tempo que o leitor se 'perde' na leitura dos poemas, ele se 'acha' em outra.

O poeta aborda temas que afligem o ser humano nessa sociedade contemporânea, uma característica própria dos escritores modernistas que está no fato de reproduzir conflitos do cotidiano, revelando questões sociais e psicológicas, revelando as inquietações que afligem o ser humano.

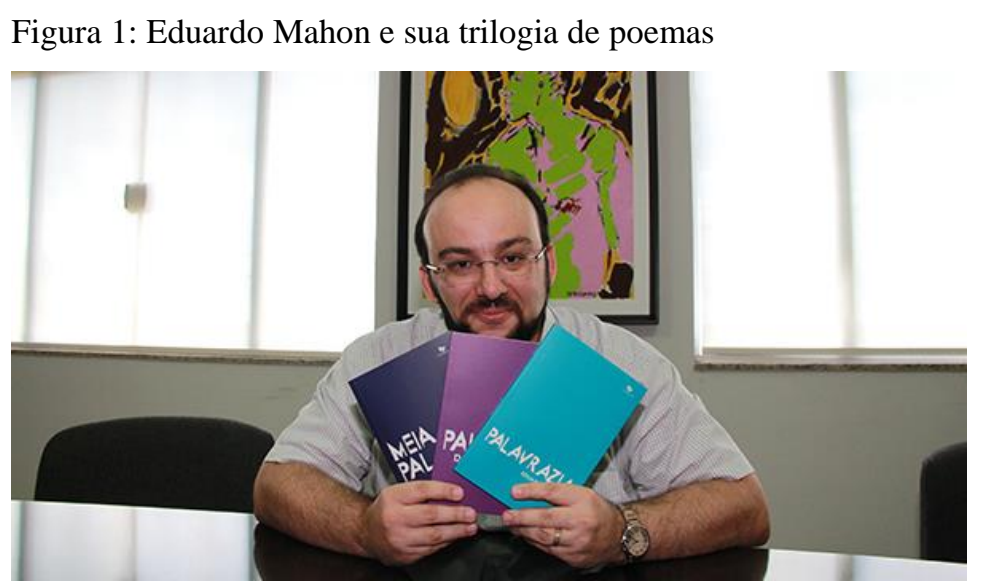

Fonte: Acervo do site particular do escritor (2019)

\section{Concisão vocabular e plurissignicação nos poemas}

Há quem diga que a poesia, quando considerada fora da sua essência pessoal, não pode ser objeto de estudo, porem os mais modernos dizem ao contrário, que ela só na sua natureza intima pode ser estudada. A análise comporta basicamente um comentário puro e simples como o levantamento de dados exteriores e a emoção poética. Observaremos o aspecto do conteúdo humano por meio da qual o poeta exprime sua visão de mundo e de homem, aspecto fundamental da arte e, portanto, da literatura. De acordo com Cortez e Rodrigues (2009, p. 89), ao analisar um poema: 
[...] três níveis de análise poderão ser considerados: o fônico (rima, ritmo, fonemas dominantes, aliterações, alternâncias, repetições, pontuação etc.), o morfossintático (tipos de frases, ligações sintáticas, categorias das palavras, como verbos, substantivos, adjetivos, entre outras) e o nível semântico compreendido pela conotação, denotação, ambiguidade, polissemia, redundância e figuras de estilo (CORTEZ; RODRIGUES, 2009, p. 89).

Diante disso, observarmos esses três níveis na análise dos poemas nas composições do escritor, mas predomina o nível semântico e o morfossintático. O escritor utiliza na composição dos poemas, expressões breves, como o próprio nome das obras sugerem, com poucas palavras, mas com plurissignificações, com interrogações, dúvidas e incertezas, que nos fazem refletir sobre a condição humana.

Existe uma predominância de substantivos e adjetivos na composição, os verbos são poucos utilizados. Nos poemas existe uma predominância do verbo "ser" na segunda pessoa do singular, "é". A repetição desse verbo que liga o sujeito ao seu predicado é, justamente, afirmar algo: " o sintoma da praga/ de olho gordo/ é vida magra".

A preferência pelos haicais em seus poemas vem do próprio estilo de trabalhar com poucas palavras, concisas e objetivas. Nos poemas, Mahon não segue a estrutura clássica do haicai composta por 17 silabas poéticas. Essa forma poética foi criada no século XVI e se popularizou pelo mundo. Com o passar o tempo, essa estrutura foi se modificando ficando a critério do poeta seguir ou não com essa métrica. Veja a métrica do poema abaixo:

\author{
$\mathrm{No} /$ hai/cai \\ $\mathrm{Su} / \mathrm{ssu} / \mathrm{rra}$ a/ in/so/lên/cia \\ o/bri/ga/do/ pe/la/ pre/fe/rên/cia
}

O primeiro verso foi composto com duas sílabas, o segundo com seis sílabas e o terceiro com nove sílabas poéticas. Não há uma preocupação na quantidade métrica dos poemas, assim cada poema tem uma quantidade de silabas poéticas diferente do outro.

A arte de compor poemas, com poucas palavras, é característica própria do escritor. São palavras selecionadas que incomodam, dão azia, causam estranhamento e perturbam o leitor, pois "só a poesia/ faz a maçã/ cair pra cima". Isaac Newton ao refletir sobre o fenômeno das coisas, criou a lei da gravidade a partir da queda de uma da maça que de acordo com sua teoria, foi atraída por uma força para o centro da terra. 
Nesses versos, o eu lírico expõe a intensidade da poesia, que foge da ordem das coisas, ela é capaz de inverter os sentidos, ou seja, é inexplicável, pois a expressão "cair pra cima" gera um desconforto, uma vez que o verbo cair indica algo que vem de cima para baixo. Vejamos outro poema:

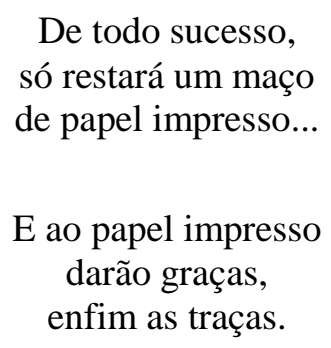

Este poema em coautoria com a escritora e, também, poeta Marta Cocco no livro Meia Palavra Vasta (2014), composto por duas estrofes com três versos cada, mostra a efemeridade da vida, demostrando quão passageira é a vida, pois de todo o sucesso que o homem tiver nessa vida, um dia, só restará a história no papel, que, futilmente, servirá de alimento para os insetos, as traças, roedoras de papel.

Podemos inferir também que esses insetos que o poema se refere são os leitores que devoram as produções dos poetas que já estão mortos fisicamente mas vivo no papel e isso serve de alimento como conhecimento cultural. A repetição da expressão "papel impresso" no final da primeira estrofe e início da terceira dá ênfase à importância do papel que serve para permanecer viva a memória de um escritor.

A rima é um recurso utilizado para obter certos efeitos especiais de sonoridade no verso, por meio da igualdade ou semelhança de sons no final das palavras, por isso, as rimas sucesso/impresso e graças/traças dinamizam a leitura do poema. Dessa forma, podemos encontrar essa ocorrência em todos os haicais nos poemas de Mahon e, por se tratar de versos curtos, fica mais fácil a memorização.

A efemeridade, também, é recorrente em seus poemas "amanhã/comemoro ou lamento/ um dia a mais ou a menos? " O eu poético demonstra nesses versos o quão imprevisível pode ser o dia de amanhã, não se tem certeza de nada, pois ao mesmo tempo que se poderá comemorar a vida, poderá lamentar, mas lamentar o quê? Esse jogo de palavras comemorar/ lamentar e mais/menos nos faz refletir sobre como a vida é irônica "um segundo/ é meu tempo/ no mundo". 
Recorrentes na trilogia, poemas com palavras minúsculas no início da frase, o desuso da vírgula e do ponto final, contrariando a regra da norma padrão. Esse comportamento do poeta em não se preocupar com o uso adequado da morfossintaxe é recorrente nos poemas, tornandose um estilo próprio do escritor em suas composições.

O eu lírico expõe sua paixão por poemas “poetizei/ que um dia/ poeta virei” de tanto ler poesia, um dia a poesia o transformou em um poeta. Percebemos a influência que a leitura possui sobre o leitor, no caso a poesia. Na palavra "poetizei" temos uma palavra composta por aglutinação com o substantivo "poeta" aquele que escreve poesia, com o verbo "usar" no sentido de "hábito ou costume".

O poeta substantiva a palavra "poetizei" para explicar como ele se transformou num poeta, mas que ao mesmo tempo, ele coloca dificuldade de compor poemas " na falta/ de tema/ criou o poema" ou "tudo dizia/ na quase/ poesia". Já dizia Bosi, "Tudo tem a sua hora: falar sobre a fala, poetar sobre a poesia, medusar- se no signo, são tendências fortes do espírito moderno" (BOSI, 1977, p. 61).

A linguagem coloquial e expressões costumeiras do cotidiano são recorrentes aos escritores modernos e, consequentemente, nos poemas de Mahon, trazendo o leitor mais próximo da realidade linguística, “ havemos de vencer/ quem muito se acha/ no meu brasão/ está escrito:/ ou vai ou racha".

Nos versos acima, no livro Palavras de Amolar (2015), Mahon homenagem Gervásio Leite, escritor mato-grossense, um dos fundadores da Universidade Federal do Mato Grosso (UFMT). Um homem muito influente no estado, foi desembargador, presidente do Tribunal de Justiça, presidente da OAB e ocupante da cadeira 2 na Academia Mato-grossense de Letras.

Em 2015 foi comemorado o centenário de Gervásio Leite, uma homenagem póstuma do Poder Judiciário do estado como forma de agradecer e reconhecer os serviços prestados por ele à Justiça. Por isso, Mahon, dedicou uma estrofe a esse homem que contribuiu de forma significante e sua memória não pode ser esquecida.

Algumas expressões utilizadas pelo poeta como “ ou vai ou racha" ou "vá se catar" são expressões coloquiais, do cotidiano, que o escritor utiliza com objetivo de aproximar o leitor ou de tornar uma leitura prática, sem rodeios.

O ofício do poeta é, também, tentar traduzir o mistério entre o sagrado e o profano com interrogação que vai mexer com o leitor “e se Jesus/ do escapulário/ for um amigo imaginário?” Com essa pergunta, o poeta faz uma indagação sobre o mítico, o sagrado, mas ao tempo o poeta 
aponta a necessidade do homem em acreditar em um 'deus' e se apoiar em um ser "Deus/ está / aqui/ ali/ e até/ Alá" pois cada povo possui seus ritos, mitos e crenças.

Outra característica própria do poeta é se manifestar como antirromântico. O movimento realismo, posterior ao romantismo, repudiavam a artificialidade dos românticos que não descreviam o mundo como ele era, vivendo de sonho e da fantasia, marcados pela subjetividade e pela emoção, voltados cada vez mais para si mesmos. No realismo, os antirromânticos abandonaram essa prática do romantismo e passaram a refletir sobre a realidade social, expondo a real situação do ser humano. Assim, o poeta procura questionar a complexidade das coisas e o comportamento do homem contemporâneo.

Nos versos "que amor?/ é virose! / talvez tuberculose", o poeta vê o amor como uma doença, algo ruim que prejudica as pessoas “toda essa alegria/ será sintoma/ de esquizofrenia”, mas ao mesmo tempo o eu lírico se demonstra confuso com o amor, pois "há quem acredite/ no amor/ com celulite" e chega até desabafar “ imagina o dano/ dizer ao amor:/ eu não te amo”. O poeta coloca o amor como um sentimento muito complicado, "desencontro/ no caminho:/ quando ela ia/ eu vinho...”. O poeta faz um trocadilho com a palavra vinha por vinho, que representa o prazer, a festa, apresentado como prazer carnal.

Na literatura, a linguagem direta, usada no seu sentido denotativo, é diferente da linguagem figurada, usada no sentido conotativo, ou seja, existe uma transposição de sentido que leva o atributo de uma palavra a um outro sentido. Quando isso acontece, chamamos de metáfora, muito comum na linguagem literária.

Essa linguagem metafórica não se confunde como forma de comparação, ela é "construída com intenção definida, visando a determinado efeito" (CANDIDO, 1996, p. 113) mas ela pode ocorrer de forma intencional dependendo do que o poeta quer expressar. Candido 1996 diz que "As pessoas mais cultas usam menos frequente a comparação intencional, mas falam incessantemente por transferências de sentido, sem perceberem" (CANDIDO, 1996, p. 112).

Encontramos na poesia de Mahon essa linguagem metafórica "poesia atira/ pontualmente/ longe da mira/"”. Nessa linguagem metafórica, o poeta coloca que só a poesia consegue atingir o alvo, o leitor, mesmo estando longe. Já nos versos "Gota que canta/ vira chuva/ o choro não/ é água muda", aqui a palavra água possui dois sentidos contrários: o de felicidade quando a gota é transformada em chuva e o sentido triste quando se remete ao choro, que de tão silencioso, imperceptível, fica mudo. 
A antítese, uma figura que trabalha com duas palavras ou ideias de sentido oposto, é recorrente nos poemas "que covardia/haver tristeza/ na alegria". Tristeza e alegria são dias palavras contrarias ou "Deus te entregue/ pro diabo/ que te carregue”. Do mesmo modo as palavras "Deus e diabo" são palavras contrarias usadas para enfatizar aquilo que quer expressar.

Existe também um paradoxo na ideia que é uma figura que se constrói com associação de termos excludentes em mesmo enunciado: "para o todo/ o muito/ é muito pouco/ o pouco/ é quase nada/ nada nunca/ é tanto". Bosi diz que "termos como ambiguidade, desvio e estranhamento remetem, em última instância, ao uso conotativo e à polissemia da palavra poética”. (BOSI, 1977, p. 208).

Assim, o poeta utiliza palavras ou termos conotativos para produzir efeito nas palavras provocando vários sentidos, gerando reflexão sobre o tema exposto.

\section{CONSIDERAÇÕES FINAIS}

Ao analisar os poemas de Eduardo Mahon, percebemos que a preocupação do poeta é produzir uma literatura que provoca interação direta com o público, criando essa tríade de autor/obra/leitor. O escritor se aproxima dos modernistas rompendo com a estrutura fixa, sem compromisso com a métrica, aplicando uma linguagem carregada de sentido, com uso de frases e estrofes curtas, poucas palavras, em cada poema, uma nova imagem, mas com um significado vasto, provocando inúmeras sensações no leitor que o faz refletir sobre o sentido da vida e das coisas.

Vale lembrar que sobre a forma e conteúdo, nenhum é mais importante que o outro, um funciona em detrimento do outro e, que a forma, se apresenta como um suporte ao conteúdo trazendo beleza a produção poética.

As produções poéticas de Eduardo Mahon são um convite ao público de leitores, admiradores de poesia, que, porventura, não conhecem sua obra. Acrescentamos que vale a pena conhecer as composições desse escritor, não somente pela sua forma estética de experimentação em sua astúcia poética, mas, principalmente, por ser um escritor brasileiro de literatura contemporânea, com produção regional no estado de Mato Grosso.

\section{REFERÊNCIAS}

BOSI, Alfredo, O ser e o tempo da poesia. São Paulo, Cultrix, Ed. da Universidade de São Paulo, 1977. 
CAMPOS, Cristina. Prefácio In: MAHON, Eduardo. Meia Palavra vasta. Cuiabá: Carlini \& Caniato, 2014.

CANDIDO, Antônio. O estudo analítico do poema. São Paulo: Humanitas

Publicações/FFLCH/USP, 1996.

D’ONOFRIO, Salvatore. Teoria do texto 2: Teoria da lírica e do drama. $1^{\text {a }}$ ed. São Paulo,

Editora Ática, 2005.

CORTEZ, C. Z.; RODRIGUES, M. H. Operadores de leitura da poesia. In: Teoria literária: abordagens históricas e tendências contemporâneas. (Org.) BONNICI, T. \& ZOLIN, L. O. $3^{\text {a }}$ Ed. Maringá: Eduem, 2009. p.59-92.

FRIEDRICH, Hugo. Estrutura da lírica moderna. Da metade do século XIX, a meados do século XX.Trad. Marise M. Curioni. São Paulo: Duas cidades,1978.

MAHON, Eduardo. Eduardo Mahon e sua trilogia de poemas. Cuiabá, 2019. Figura 1.

MAHON, Eduardo. Vida Gazeta Digital [Entrevista cedida a] Angélica Moraes, na plataforma da Academia Mato-grossense de Letras em abr. 2016.

MAHON, Eduardo. Meia Palavra Vasta. Cuiabá- MT: Carlini \& Carniato Editorial, 2014.

MAHON, Eduardo. Palavra de Amolar. Cuiabá- MT: Carlini \& Carniato Editorial ,2015.

MAHON, Eduardo. Palavrazia. Cuiabá- MT: Carlini \& Carniato Editorial ,2015.

MAHON, Eduardo. Escritor Eduardo Mahon e sua trilogia. Figura 1, 2019.

NETO, João Antônio. Apresentação do livro In: MAHON, Eduardo. Palavrazia. Cuiabá: Carlini \& Caniato, 2015.

PAZ, Octavio. Signos em Rotação. 2a ed. São Paulo: Editora Perspectiva S.A,1990.

POE, Edgar Allan. Teorias e ensaios. Globo, Rio de Janeiro, 1985.

RIBEIRO, Marilza. Prefácio In: MAHON, Eduardo. Palavra de amolar. Cuiabá: Carlini \& Caniato, 2015.

WALKER, Marli. Prefácio. In: MAHON, Eduardo. Palavrazia. Cuiabá: Carlini \& Caniato, 2015. 